\title{
Time Scale of Chloride-Induced Corrosion on Circular Section RC Linked Accelerated Test to Natural Corrosion
}

\author{
Yue Zhang, ${ }^{1}$ Fangyan Lan, ${ }^{2}$ Mi Zhou ${ }^{1},{ }^{2}$ and Ke Wang ${ }^{3}$ \\ ${ }^{1}$ School of Civil Engineering, Xi'an University of Science and Technology, Xi'an 710054, China \\ ${ }^{2}$ Key Laboratory for Old Bridge Detection and Reinforcement Technology of the Ministry of Transportation, Chang'an University, \\ Xi'an 710054, China \\ ${ }^{3}$ School of Civil Engineering, Harbin Institute of Technology, Harbin, Heilongjiang 150090, China \\ Correspondence should be addressed to Mi Zhou; zhoumi@chd.edu.cn
}

Received 19 October 2020; Revised 12 December 2020; Accepted 7 January 2021; Published 22 January 2021

Academic Editor: Shangtong Yang

Copyright (C) 2021 Yue Zhang et al. This is an open access article distributed under the Creative Commons Attribution License, which permits unrestricted use, distribution, and reproduction in any medium, provided the original work is properly cited.

\begin{abstract}
The time scale in accelerated decay is essential for studying the durability of reinforced concrete (RC) structures exposed to the chloride corrosion environment. An accelerated corrosion test (ACT) was carried out on RC specimens were conducted under different chloride concentrations and applied voltages, with the information of steel measured. A novel prediction model of the complete corrosion process is proposed to evaluate the time correlation between accelerated decay and natural corrosion. The corrosion process of RC is divided into two stages: corrosion initial stage and corrosion stage of reinforcement. For the first stage, the coefficient of circular section members is presented. For the second stage, the accelerated factor of the test for the natural environment is proposed based on the Arrhenius-type and Faraday's law. It is calculated by making regressions among some values of parameters, while moving to natural corrosion are extrapolating. The accelerating effect of applied voltages increases in the low-chloride environment, which is better than that in the high-chloride environment. This study provides calibration of the time scale for laboratory tests to analyze the performance of RC structures after corrosion.
\end{abstract}

\section{Introduction}

Chloride-induced corrosion is the key cause of damage and deterioration of reinforced concrete (RC) structures $[1,2]$. Many research explored the durability and mechanical properties of RC structures based on the accelerated corrosion test (ACT) [3-9] (see Table 1). Visible effects on the structure may take several years since its corrosion in the natural environment is a long-time and slow process. It uses electrical energy to promote the chemical reaction, which destroys the electrochemical equilibrium of steel and increases the thermodynamic instability of steel by applying voltage.

An electrochemical reactor consists of a steel bar-solution system and a stainless-steel solution system and continuously extracts electrons from one end and deliver them to the other end $[7,8]$. Since the electron $\left(e^{-}\right)$cannot enter the aqueous solution, the electrode reactions occurred at the metal-solution interface, as shown in equations (1) and (2).

$$
\begin{aligned}
& \text { Andoic reaction } \mathrm{Fe} \longrightarrow \mathrm{Fe}^{2+}+2 e^{-}, \\
& \text {Cathodic reaction } 2 \mathrm{H}^{+}+2 e^{-} \longrightarrow \mathrm{H}_{2} .
\end{aligned}
$$

However, a challenging problem that arises in this domain is that relationship between time exposures under natural and accelerated aging is hard to evaluate. Butke [10] has made a preliminary exploration, and the physical process of chloride erosion is divided into two stages (Figure 1). The first stage is corrosion initiation, governed by the intrusion of chloride ions. The alkaline environment of concrete results in the formation of a passive film on the steel surface, which can protect the steel from corrosion. When chloride ions penetrate the concrete, and the chloride concentration on the steel reaches a threshold value, the steel bar becomes depassivated and corrosion begins. The second stage is the corrosion stage of reinforcement. After corrosion begins, steel is consumed and corrosion products (rust) are formed at the interface zone 
TABLE 1: Previous research studies based on the ACT.

\begin{tabular}{|c|c|c|c|c|c|c|}
\hline & $\begin{array}{l}\text { Yalciner et al. } \\
{[3]}\end{array}$ & Kang et al. [4] & Yuan et al. [5] & Jin et al. [7] & $\begin{array}{c}\text { Imperatore et al. } \\
{[8]}\end{array}$ & $\begin{array}{c}\text { Nossoni and } \\
\text { Harichandran [9] }\end{array}$ \\
\hline $\begin{array}{l}\text { Test } \\
\text { method }\end{array}$ & $\begin{array}{l}\text { Potentiostatic } \\
\text { method }\end{array}$ & Potentiostatic method & $\begin{array}{c}\text { Galvanostatic } \\
\text { method }\end{array}$ & Potentiostatic method & $\begin{array}{l}\text { Galvanostatic } \\
\text { method }\end{array}$ & $\begin{array}{l}\text { Galvanostatic } \\
\text { method }\end{array}$ \\
\hline $\begin{array}{l}\text { Chloride } \\
\text { content }\end{array}$ & $3.5 \%$ & $\begin{array}{c}1.95 \% \\
\text { chloride }+0.27 \% \\
\text { sulfate radical }\end{array}$ & $3.5 \%$ & $\begin{array}{c}1.50 \% \\
\text { chloride }+0.50 \% \\
\text { sulfate radical }\end{array}$ & $3 \%$ & $0.5 \%-10 \%$ \\
\hline $\begin{array}{l}\text { Voltage/ } \\
\text { current }\end{array}$ & $60 \mathrm{~V}$ & $30 \mathrm{~V}$ & $1.31 \mathrm{~A}$ & $30 \mathrm{~V}$ & About $0.10 \mathrm{~mA}$ & $1.85-3.64 \mathrm{~A}$ \\
\hline $\begin{array}{l}\text { Studying } \\
\text { object }\end{array}$ & Square RC pier & Square RC pier & $\begin{array}{c}\text { Square and } \\
\text { circular RC pier }\end{array}$ & Square RC pier & Net bar & Concrete cube \\
\hline
\end{tabular}

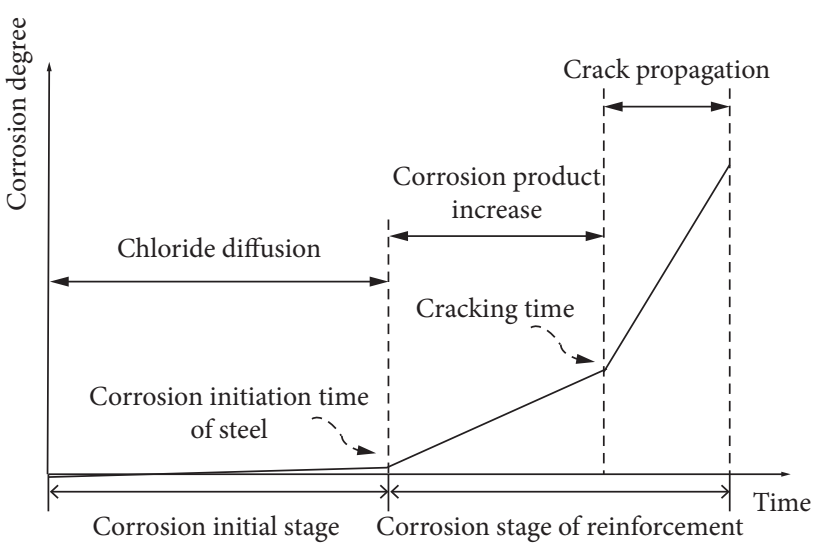

Figure 1: Chloride-induced degradation model of RC.

between the concrete and steel due to chemical reactions with moisture and oxygen. The corrosion products expand continuously, resulting in cracks and failure of components $[11,12]$.

Faraday's law has been widely adopted to predict the damage degree of specimens after ACT. However, in the early stage of accelerated decay, chloride cannot diffuse to the surface of reinforcement. There are two competitive reactions at the anode between oxidation of steel and oxygen production, and part of the applied electric energy was consumed in the electrolytic water reaction, which made the mass loss calculated by Faraday's proportionality inaccurate. Moreover, the galvanostatic method is mostly adopted to facilitate the calculation $[5,6,8]$, but the deterioration process of structures can be intuitively obtained through the current change using the potentiostatic method. Besides, it is difficult to calibrate the natural erosion time corresponding to the ACT at this stage, and most of the previous research studies adopt empirical models [3-6]. There are limitations and inaccuracies in the current methods. Therefore, a new approach to evaluate the relationship between the accelerated test and the decay under natural exposure is developed.

The present study intends to provide the calibration of natural erosion time corresponding to the ACT. It is significant for predicting the durability and mechanical properties of RC columns in the saline soil environment and coastal areas.

\section{Materials}

\subsection{Specimen Preparation}

2.1.1. Material Parameter. Portland cement in accordance with Chinese standard (GB175-2007), with a compressive strength of $30 \mathrm{MPa}$, was used for this study. Mix ingredients and proportions per cubic meter of concrete are $411 \mathrm{~kg}$ cement, $185 \mathrm{~kg}$ water, $559 \mathrm{~kg}$ sand of maximum sand size $0.5 \mathrm{~mm}$, and $1245 \mathrm{~kg}$ aggregate of maximum size $40 \mathrm{~mm}$. The parameters of materials are shown in Table 2.

2.1.2. Specimen Details. RC specimens were cast as a circular section column $(\Phi 50 \times 150 \mathrm{~mm})$ and prepared with $20 \mathrm{~mm}$ cover depths of a single $10 \mathrm{~mm}$-diameter embedded steel bar as the anode. A stainless-steel bar (diameter of $8 \mathrm{~mm}$ ) was the cathode. The specimen details can be found in Figure 2. Two days after casting and protection in PVC molds, the specimens were stripped and subsequently cured in water at $23 \pm 2^{\circ} \mathrm{C}$ for another 7 days. Corrosion testing was carried out at the RC age of 9 days.

2.2. Test Equipment. In the ACT, external electric energy is applied to promote the corrosion using the direct-current power supply (unit type: MP601D). During the test, the current flows inside and outside the battery to form a circuit. The solution temperature and ambient temperature during the test are continuously monitored (unit type: NTC(10 K/ 3435)). The test schematic diagram and corresponding unit type are shown in Figure 2. The residual mass of corroded steel bar is measured by weighing.

\section{Methodology}

3.1. Test Condition. The chloride concentration varies significantly in different regions, such as 1.2\% in Qinghai Lake (Gangca County, China, $100^{\circ} 2090^{\prime} \mathrm{E} 37^{\circ} 0455^{\prime} \mathrm{N}$ ), $3.5 \%$ in the Pacific Ocean (Guangzhou, China, $113^{\circ} 1822^{\prime} \mathrm{E} 23^{\circ} 1012^{\prime} \mathrm{N}$ ), and $4 \%$ in the Red Sea (Aden, Yemen, $\left.45^{\circ} 1201^{\prime} \mathrm{E}, 12^{\circ} 4523^{\prime} \mathrm{N}\right)$. Considering regional differences and the range of chloride ion concentrations commonly used in the study (see Table 1), the chloride concentrations of the test were set as $1.5 \%, 3.5 \%$, and $5 \%$. Taking into account the applied voltage ranges commonly used in the study (see Table 2) and the prescribed 


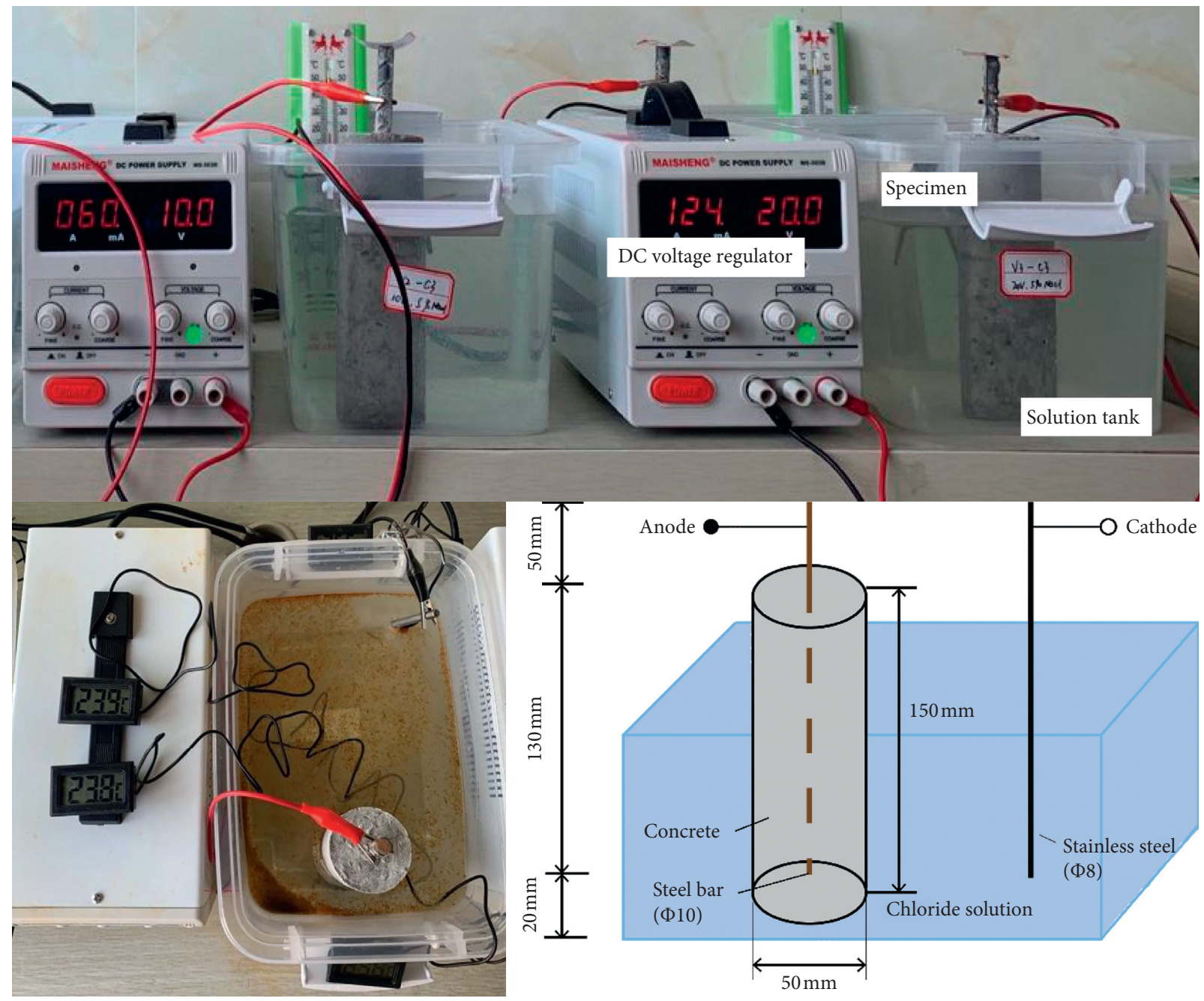

DC voltage regulator: MP601D; Concentration of chloride solution: 1.5\%, 3.5\% and 5\%; Temperature sensor: NTC (10K/3435); Immersion depth of specimen: $130 \mathrm{~mm}$.

Figure 2: Schematic diagram of the test system.

TABLE 2: Parameters of materials.

\begin{tabular}{lcccc}
\hline Materials & $R_{m}(\mathrm{MPa})$ & $\sigma_{\mathrm{bc}}(\mathrm{MPa})$ & $E(\mathrm{MPa})$ & $\gamma\left(\mathrm{kg} / \mathrm{m}^{3}\right)$ \\
\hline Steel bar (HRB335) & 300 & 300 & 200000 & 7850 \\
Concrete (C30) & 3 & 30 & 30000 & 2385 \\
\hline
\end{tabular}

Note. $R_{m}$ : tensile strength; $\sigma_{\mathrm{bc}}$ : compressive strength; $E$ : elasticity modulus; $\gamma$ : density.

voltage class for personal safety, it was set as $1 \mathrm{~V}, 5 \mathrm{~V}$, $10 \mathrm{~V}, 20 \mathrm{~V}, 35 \mathrm{~V}$, and $55 \mathrm{~V}$. The test matrix is listed in Table 3.

The accelerated effect was very weak in the condition with an applied voltage of $1 \mathrm{~V}$, and the samples with an applied voltage of $55 \mathrm{~V}$ caused a significant increase in the solution temperature during the test, which will obviously enhance the accelerated corrosion of components. Therefore, the results under these two voltages were not discussed in this paper.
3.2. Corrosion Initiation Stage. In the laboratory, the cured specimens were immersed in the salt solutions and accelerated by low current for 2 days. This method referring to the test in previous studies [5, 9] had two purposes: (1) the specimens were immersed in the solution during the test to increase conductivity and (2) to diffuse the chloride ion to the surface of the steel bar fully.

In the corrosion initiation stage of ACT, the process of the anode reaction is divided into three parts (Figure 3). In the first part, the chloride ion has not diffused to the steel surface. The applied electric energy is all consumed in the electrolytic water reaction, which leads to the continuous consumption of $\mathrm{OH}^{-}$in the anode. In the second part, the chloride ion diffuses to the steel surface. Two reactions of electrolytic water and oxidation of steel co-occur at the anode and compete with each other for electrical energy. Finally, with the incessant invasion of $\mathrm{Cl}^{-}$and the continuous consumption of $\mathrm{OH}^{-}$, the $\left[\mathrm{Cl}^{-} / \mathrm{OH}^{-}\right]$ion on the steel surface increases until all the 
TABle 3: Test matrix.

\begin{tabular}{|c|c|c|c|}
\hline Specimen & Chloride concentration (\%) & Current (corrosion initiation stage) (A) & Voltage (corrosion stage of reinforcement) (V) \\
\hline B1-1 & 1.5 & & \\
\hline B1-2 & 3.5 & & 1 \\
\hline B1-3 & 5.0 & & \\
\hline B2-1 & 1.5 & & \\
\hline B2-2 & 3.5 & & 5 \\
\hline $\mathrm{B} 2-3$ & 5.0 & & \\
\hline B3-1 & 1.5 & & \\
\hline B3-2 & 3.5 & & 10 \\
\hline B3-3 & 5.0 & & \\
\hline B4-1 & 1.5 & 0.0072 & \\
\hline B4-2 & 3.5 & & 20 \\
\hline B4-3 & 5.0 & & \\
\hline B5-1 & 1.5 & & \\
\hline B5-2 & 3.5 & & 35 \\
\hline B5-3 & 5.0 & & \\
\hline B6-1 & 1.5 & & \\
\hline B6-2 & 3.5 & & 55 \\
\hline B6-3 & 5.0 & & \\
\hline
\end{tabular}

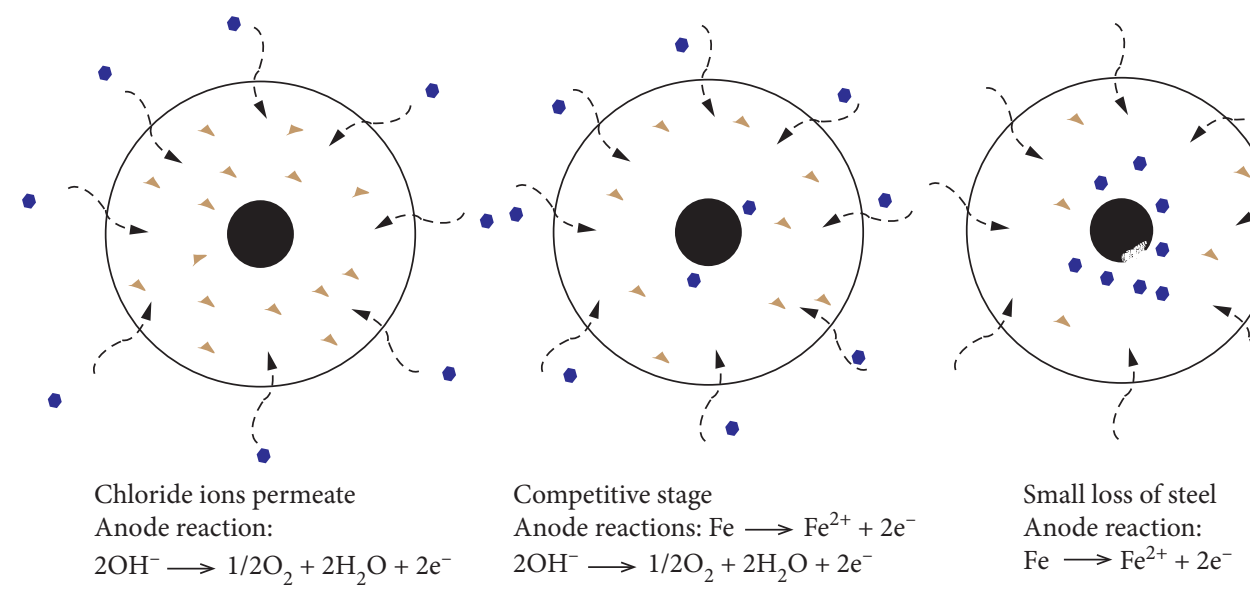

- $\mathrm{Cl}^{-}$

$\triangle \mathrm{OH}^{-}$

FIgURE 3: Anodic reactions of ACT.

electric energy is consumed in the oxidation of steel. It is challenging to determine the corrosion initiation time of steel in the ACT because of the competition stage.

Fick's second law (equation (3)) was widely used to discuss the diffusion of chloride ions [4-6, 13, 14], but its one-dimensional diffusion in the plane depth direction is not applicable to the circular cross section. RC members with circular section have the characteristics of axisymmetric. Under the assumption of uniform ambient conditions and concrete materials, chloride ions will diffuse along the radius direction of the members. Combining Fick's second law, the diffusion of chloride ions in the circular cross section is expressed in equations (3) and (4).

$$
\begin{aligned}
\frac{\partial C}{\partial t} & =D\left(\frac{\partial^{2} C}{\partial x^{2}}+\frac{\partial^{2} C}{\partial y^{2}}\right), \\
\frac{\partial C}{\partial t} & =D\left(\frac{\partial^{2} C}{\partial R^{2}}+\frac{\partial C}{\partial R} \cdot \frac{1}{R}\right), \\
C(t=0, R=0) & =0, \\
\frac{\partial C}{\partial R}(R=0) & =0,
\end{aligned}
$$

where $D$ is the diffusion coefficient; $C$ is the chloride content in concrete; $R$ is the depth that chloride ions penetrate concrete; $t$ is the time of erosion. 
When the chloride content on the steel surface reaches the threshold value $C_{\mathrm{cr}}, C(x, t)=C_{\mathrm{cr}}$, the steel starts to rust. Thus, corrosion initiation time $T_{\text {corr }}$ can be deduced.

$$
T_{\text {corr }}=k \cdot \frac{d_{c}^{2}}{4 D}\left[\operatorname{erf}^{-1}\left(1-\frac{C_{\mathrm{cr}}}{C_{0}}\right)\right]^{-2},
$$

where $k$ is the coefficient of circular section member; $d_{c}$ is the cover depth of reinforcement; $C_{\mathrm{cr}}$ is the critical chloride content; and $C_{0}$ is the chloride content of the concrete surface.

3.3. Corrosion Stage of Reinforcement. In this stage, the ACT promotes the corrosion reaction by applying constant voltages to the specimen, and the reaction rate is strongly influenced by the chloride concentration and the applied voltage [15-17]. The Arrhenius-type relationship is commonly used to define the accelerating effect of increased temperature on the maturity of RC members $[16,18,19]$. It can be estimated using equation (6).

$$
t_{e}=\int \beta_{T} \mathrm{~d} t,
$$

with the thermal activation coefficient:

$$
\beta_{T}=e^{\left(E_{a} / R\right)\left(\left(1 / T_{0}\right)-(1 / T)\right)} .
$$

Caceres et al. studied the law of accelerating stiffness degradation of fiber concrete with temperature increasing based on this relationship [20]. Gideon and Paul found that the accelerating law of chloride ions on the corrosion degree of RC strain hardening cement-based composite also conforms to the Arrhenius-type law when the applied voltage increased and the cover depth decreased [21]; furthermore, a potential relationship between this method and the durable life design of the structure is also proposed. This study assumes that the accelerated corrosion of the steel bar is similar to Arrhenius-type when the voltage and chloride content increase, which have been verified in the ACT and quality loss test of the steel bar [21-23].

\section{Results and Discussion}

\subsection{Corrosion Initiation Time of Steel}

4.1.1. Mass Loss. Because the specimens were exposed to an aggressive environment for 2 days, the steel slightly corroded (see Section 3.2). The anode was weighed before and after the test to estimate the mass loss in the first stage. The mass loss of each specimen is presented in Figure 4. The test varied from $0.40 \%$ to $0.62 \%$ of its original weight, depending on the chloride concentration.

First of all, the results of the present study are within the range proposed in a previous study [9], and the mass losses of steels of the five specimens under the same chloride concentration are similar, indicating that the results are reliable. From Figure 4, the mass loss increases with the

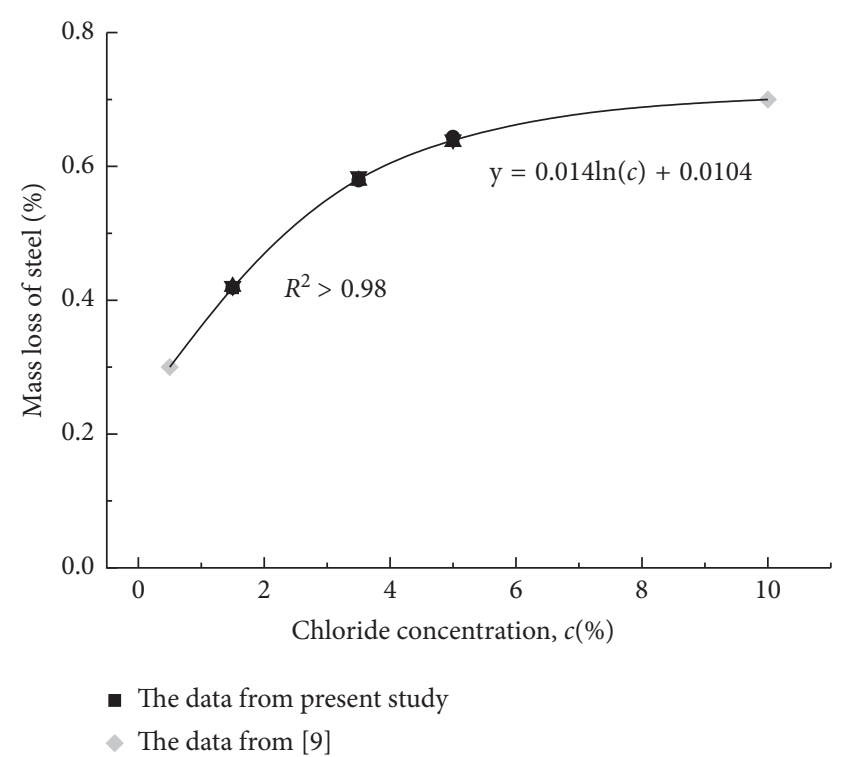

Figure 4: Mass loss at the corrosion initiation stage.

increase in chloride concentration. The reason is that the diffusion of chloride ions is accelerated by the difference of content between inside and outside concrete, and the chloride content on the steel surface reaches the critical content earlier, which reduces the time spent in chloride ions diffusion and in the competition stage. Electrical energy is more consumed in the oxidation of steel, leading to more mass loss. The increased amplitude of mass loss decreases gradually with the increase of chloride concentration, which is consistent with the law in [9]. Therefore, a logarithmic relationship between the mass loss and the chloride concentration is speculated, but it needs to be confirmed by more experimental data.

4.1.2. Parameter of Corrosion Initial Time. The value of relevant parameters $k, C_{0}, C_{\mathrm{cr}}$, and $D$ determines the corrosion initial time of steel bar in the natural exposed environment $T_{\text {corr }}$. Wang proved that $k$ is independent of the chloride diffusion coefficient $D$ and is related to the chloride content on the concrete surface $C_{0}$, radius of member $R_{0}$, and the cover depth $d_{c}$ [24]. By further sorting out the experimental data in [24], the change of the coefficient $k$ with the chloride concentration can be obtained on the premise that the cover depth is $20 \mathrm{~mm}$ and the radius of member is $25 \mathrm{~mm}$.

$$
\begin{aligned}
k= & 0.9114+1.266 c+0.00016 R-8.649 c^{2}-0.0006 c R \\
& -1.046 R^{2} \times 10^{-7},
\end{aligned}
$$

where $c$ is the chloride concentration in the ACT and equal to $C_{0}$ in the natural exposure environment; and $R$ is the diameter of the member.

The parameters $C_{0}, C_{\mathrm{cr}}$, and $D$ can be estimated by equations (9)-(11) [25]. 


$$
\begin{aligned}
& C_{0}(d)=\left\{\begin{array}{l}
2.95 \mathrm{~kg} / \mathrm{m}^{3}, \quad d<0.1 \mathrm{~km}, \\
1.15-1.81 \log _{10}(d) \frac{\mathrm{kg}}{\mathrm{m}^{3}} \quad 0.1 \mathrm{~km}<d<2.84 \mathrm{~km}, \\
0.03 \frac{\mathrm{kg}}{\mathrm{m}^{3}}, \quad d>2.84 \mathrm{~km},
\end{array}\right. \\
& C_{\mathrm{cr}}=0.9 \frac{\mathrm{kg}}{\mathrm{m}^{3}}, \\
& D=D_{\mathrm{H}_{2} \mathrm{O}} 0.15 \frac{1+\rho_{c}(c / w)}{1+\rho_{c}(c / w)+\left(\rho_{c} / \rho_{a}\right)(a / c)}\left(\frac{\rho_{c}(c / w)-0.85}{1+\rho_{c}(c / w)}\right)^{3}\left(\frac{\mathrm{cm}^{2}}{\mathrm{~s}}\right)
\end{aligned}
$$

where $a / c$ is the aggregate-to-cement ratio, $\rho_{c}$ and $\rho_{a}$ are the mass densities of cement and aggregates, respectively; $D_{\mathrm{H}_{2} \mathrm{O}}$ is the chloride diffusion coefficient in an infinite solution $\left(=1.6 \times 10^{-5} \mathrm{~cm}^{2} / \mathrm{s}\right.$ for $\left.\mathrm{NaCl}\right)$; and $w / c$ is the water-cement ratio.

\subsection{Corrosion Time of Reinforcement}

4.2.1. Current Variation. Test duration of corrosion stage of reinforcement $\left(150 \mathrm{~h}, 100 \mathrm{~h}\right.$, and $40 \mathrm{~h}$; marked as $\left.t_{2}\right)$ was divided into 15 equal parts $\left(t_{d}\right)$ to analyze the current change, and the ratio of the average current of each divided duration $\left(I_{t}\right)$ to the average current of the whole test period $\left(I_{0}\right)$ varies with time, as shown in Figure 5.

It can be seen in Figure 5 that the current in the entire test period decreases first, then increases, and finally tends to be stable. A sustained decrease of corrosion current with the aggravation of corrosion in the early stage, since the accumulation of corrosion products leads to the gradual increase of the resistivity of the system. When cracks through the concrete cover and corrosion solution to flow directly to the steel surface, the current suddenly increases. Until the solution in the concrete is saturated, the current tends to be stable. All specimens cracked at about $2 / 3$ of the acceleration time.

4.2.2. Crack Characteristics of Samples. The cracks appeared earlier and expanded rapidly at high voltages and highchloride concentrations. The formation and accumulation of corrosion products exert pressure on the concrete surrounding the steel bar. Once the tensile strength of the concrete is reached, corrosion-induced cracking occurs, as shown in Figure 6. The specimens developed longitudinal cracks parallel to the steel bar. In the condition of chloride concentration of $5 \%$ and voltage of $10 \mathrm{~V}, 20 \mathrm{~V}$, and $35 \mathrm{~V}$, respectively, the cracks were parallel to the steel bar in the longitudinal direction (as the cracking characteristics of specimens of B3-3, B4-3, and B5-3 in Figure 6(a)). In the transverse direction, corrosion products were uniformly distributed in the circumferential direction of the steel bar. Transverse penetrating cracks appeared in $1 / 3$ height to $1 / 2$ height of the specimen, as shown in Figure 6(b). Besides, from Figure 6(c), the wedge-shaped failure was showed in transverse. The cracking conforms to the propagation pattern of uniform rust expansion crack, which illustrates that the applied voltage has a significant influence on the corrosion rate and little influence on the cracking characteristics.

4.2.3. Mass Loss. Quality determinations of all steel bars were carried out before and after the two-stage test. After the ACT, corrosion products were removed by brushing them with a steel-wire mesh and subsequently cleaning with deionized water without disturbing the base metal. The details of this preparation can be found in the previous studies [22, 26]. Table 4 summarizes the mass losses of the specimens with a height of $130 \mathrm{~mm}$ and an initial mass of the steel bar of $80 \mathrm{~g}$ after the ACT under three chloride concentrations and four voltages, and the logarithmic treatment was carried out. The masses of the deteriorated steel were determined only at the end of the test, and more data points were needed to derive the time scale. Moreover, it is notable that the actual mass loss in this stage was determined by subtracting the mass loss in the corrosion initiation stage from the total mass loss measured.

Note that the masses of the deteriorated steel bars were determined only at the end of the tests. To obtain more data points in Figure 7, the average mass losses at more time points were calculated based on Faraday's proportionality of steel mass loss to the corrosion current (Equation (12)).

$$
\Delta m=\frac{A_{m}}{n F} \int_{0}^{t_{2}} I(t) \mathrm{d} t,
$$

where $\Delta m$ is the steel loss in grams, $I(t)$ is the measured current in amperes at time $t$, and $t_{2}$ is the duration of the test of the second stage. $A_{m}$ is the atomic mass of Fe, $n$ is the valency (assuming that the rust product is mainly iron hydroxide $\mathrm{Fe}(\mathrm{OH})_{2}, n=2$ ), and $\mathrm{F}$ is the Faraday's constant ( 96485 coulombs per $\mathrm{mol}$ ).

The mass losses at $1 / 2$ and $2 / 3$ of the ACT duration were estimated using equation (12). Figure 6 shows the remaining masses of steel, starting from a nominal, undamaged $80 \mathrm{~g}$ per 


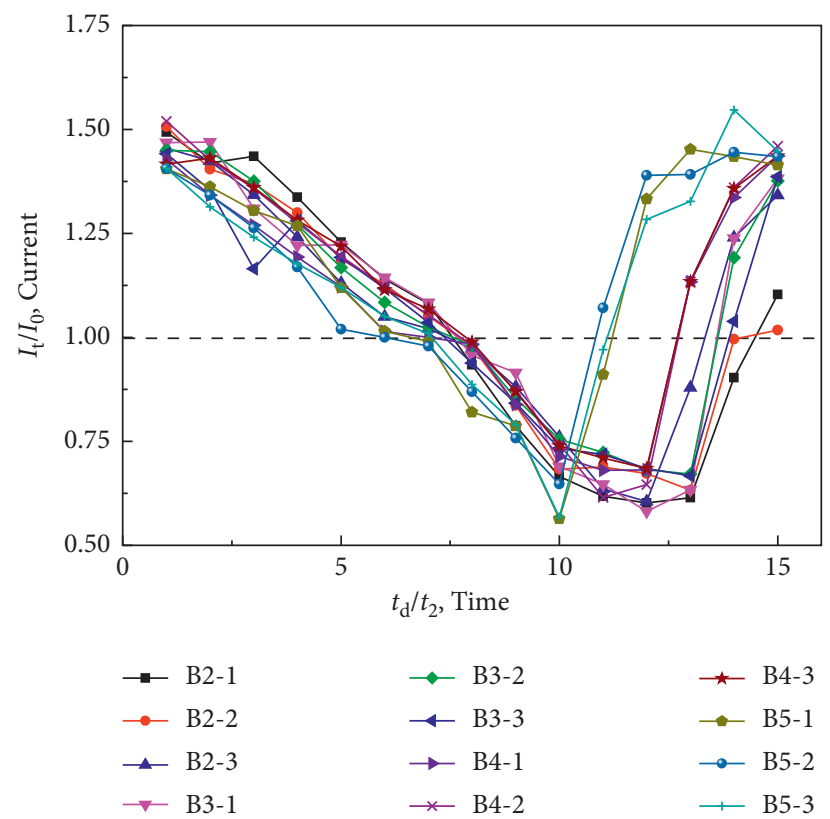

Figure 5: Plots of the current during the test as a function of time $\left(t_{d} / t_{2}\right)$ at each condition.

$130 \mathrm{~mm}$-long steel bar, after having been subjected to ACT. A logarithmic scale for each axis was used.

As showing in Figure 7, the residual mass of RC specimens under different chloride contents was obtained based on the ACT. The mass loss is greater at high-chloride concentrations (for example, at the voltage of $35 \mathrm{~V}$, the mass loss is $12.48 \mathrm{~g}$ at the concentrations of $1.5 \%, 14.04 \mathrm{~g}$ at the concentrations of $3.5 \%$, and $21.43 \mathrm{~g}$ at the concentration of $5 \%$ ), and it is greater at high applied voltages (for example, at the chloride concentration of $5 \%$, the mass loss is $5.06 \mathrm{~g}$ under $5 \mathrm{~V}, 6.76 \mathrm{~g}$ under $10 \mathrm{~V}, 11.20 \mathrm{~g}$ under $20 \mathrm{~V}$, and $21.43 \mathrm{~g}$ under $35 \mathrm{~V}$ ).

4.2.4. Accelerated Factor. The relationship between the accelerated decay and the decay under long-term testing under natural exposure in regions where such deterioration occurs is expressed through an accelerated factor $k$. The accelerated factor is the ratio between time exposures under natural and accelerated aging to a similar level of deterioration. For example, in the ACT, an accelerated factor $k=10$ means that the degradation that occurs in RC in the period of one year under accelerated laboratory corrosion test conditions represents the deterioration in such a RC structure over a period of 10a under the natural environmental conditions in coastal regions or practice of salt-based de-icing.

To obtain the law of accelerated factors under various conditions, a reference voltage $(5 \mathrm{~V})$ was defined temporarily and each curve shifts onto it. The shifting distance of each curve was defined as its shift factor. Draw the master curve as the superimposition of the individual curves shifted onto the reference curve. Figure 8 shows the timeresidual mass curve of three chloride concentrations and the reference voltage of $5 \mathrm{~V}$.
Based on Arrhenius time equivalence, the $10 \mathrm{~V}, 20 \mathrm{~V}$, and $35 \mathrm{~V}$ curves are shifted in the lg-lg domain of Figure 7 to link to the experimental $5 \mathrm{~V}$ curve, thereby representing an equivalent $5 \mathrm{~V}$ curve $[17,18]$. In this case, the shift factors are $0.17,0.64$, and 1.34 for the $10 \mathrm{~V}, 20 \mathrm{~V}$, and $35 \mathrm{~V}$ curves, respectively, for the $1.5 \%$ chloride concentration; $0.16,0.60$, and 1.30 for the $10 \mathrm{~V}, 20 \mathrm{~V}$, and $35 \mathrm{~V}$ curves, respectively, for $3.5 \%$ chloride concentration; and $0.15,0.58$, and 1.27 for the $10 \mathrm{~V}, 20 \mathrm{~V}$, and $35 \mathrm{~V}$ curves, respectively, for $5 \%$ chloride concentration.

Use data-fitting to find the shift factor law. To better fit the data and make the data curve more consistent with the law of exponential function, all data are increased by 0.5 . The derivation of the shift factor of $0 \mathrm{~V}$ is shown in Figure 9.

The shift factor of $0 \mathrm{~V}$ can be obtained by extrapolating the trend lines in Figure 9. Exponential trend lines fit the three sets of shift values closely with $R^{2}>0.98$. The final value of the shift factor of $0 \mathrm{~V}$ is 0.5 minus the intersection with the vertical axis. The shift factor is 0.14 by extrapolating in Figure 9

The $5 \%$ chloride concentration is defined as the reference concentration. All curves of $5 \mathrm{~V}$ shift to the left by $0.14(0 \mathrm{~V}$ curve), and the main curves of different chloride concentrations are linked to the main curves of 5\% chloride concentration. The deterioration of RC members with 5\% chloride concentration in the natural exposure environment can be obtained in Figure 10.

The curve in Figure 10 shows the correlation between the logarithm of the residual mass and the logarithm of time, and it represents mass deterioration of RC specimens without applied voltages and submersed in 5\% chloride concentration. The time scale $(\alpha)$ can be calculated by comparing the mass loss of the steel bar under the natural exposure environment $(0 \mathrm{~V})$ with the mass loss measured by the ACT at any applied voltages. Specifically, the specimen 


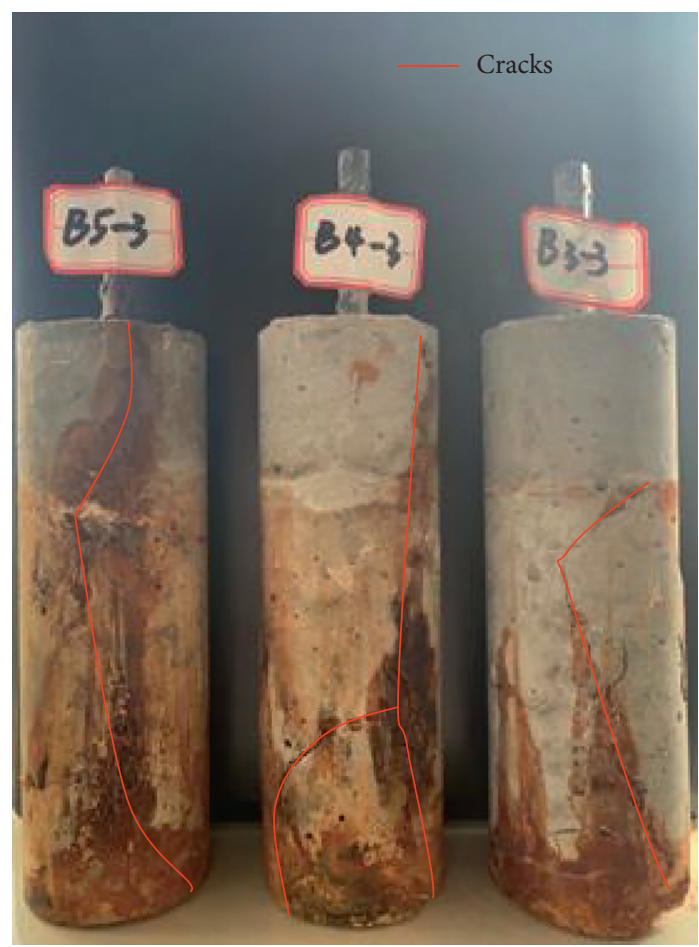

(a)

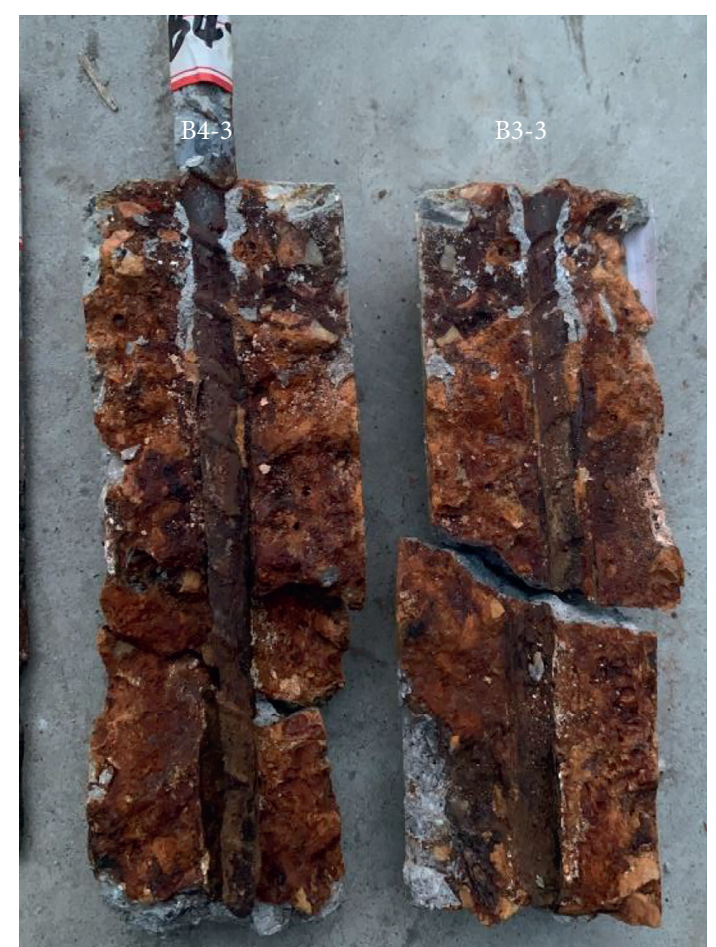

(b)

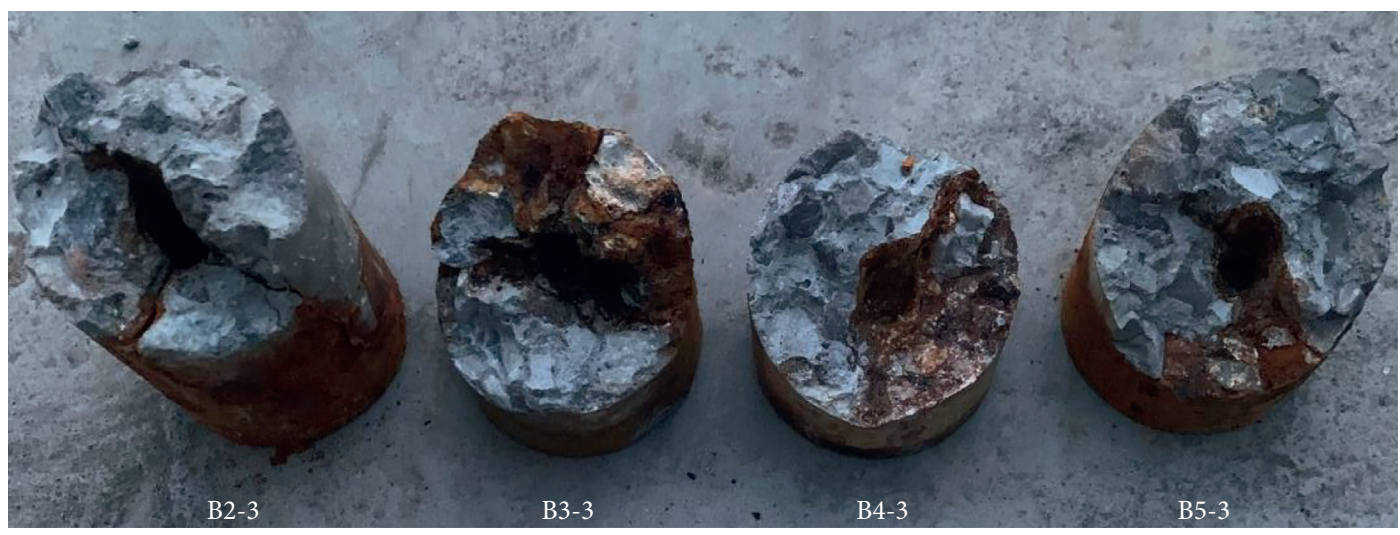

(c)

Figure 6: Crack characteristics and damage degrees of samples. (a) Cracks. (b) Longitudinal. (c) Transverse.

TABLe 4: Mass loss and the logarithm of residual mass of steel.

\begin{tabular}{|c|c|c|c|c|c|c|}
\hline $\begin{array}{l}\text { Voltage } \\
(\mathrm{V}) \\
\end{array}$ & $\begin{array}{c}\text { Chloride concentration } \\
(\%)\end{array}$ & $\begin{array}{l}\text { Mass loss in the first stage } \\
(\mathrm{g})\end{array}$ & $\begin{array}{l}\text { Mass loss in the second stage } \\
(\mathrm{g})\end{array}$ & $\begin{array}{l}\text { Log } \\
(\mathrm{M})\end{array}$ & $\begin{array}{l}\text { Acceleration time } \\
(\mathrm{h})\end{array}$ & $\log (\mathrm{T})$ \\
\hline \multirow{3}{*}{5} & 1.5 & 0.32 & 2.52 & 1.8910 & \multirow{3}{*}{150} & \multirow{3}{*}{2.1761} \\
\hline & 3.5 & 0.45 & 3.24 & 1.8877 & & \\
\hline & 5 & 0.53 & 5.06 & 1.8778 & & \\
\hline \multirow{3}{*}{10} & 1.5 & 0.32 & 3.44 & 1.8847 & \multirow{3}{*}{150} & \multirow{3}{*}{2.1761} \\
\hline & 3.5 & 0.47 & 4.35 & 1.8815 & & \\
\hline & 5 & 0.53 & 6.76 & 1.8679 & & \\
\hline \multirow{3}{*}{20} & 1.5 & 0.31 & 6.66 & 1.8672 & \multirow{3}{*}{100} & \multirow{3}{*}{2.0000} \\
\hline & 3.5 & 0.46 & 7.35 & 1.8640 & & \\
\hline & 5 & 0.53 & 11.20 & 1.8409 & & \\
\hline \multirow{3}{*}{35} & 1.5 & 0.32 & 12.48 & 1.8315 & \multirow{3}{*}{40} & \multirow{3}{*}{1.6021} \\
\hline & 3.5 & 0.46 & 14.04 & 1.8223 & & \\
\hline & 5 & 0.53 & 20.37 & 1.7716 & & \\
\hline
\end{tabular}




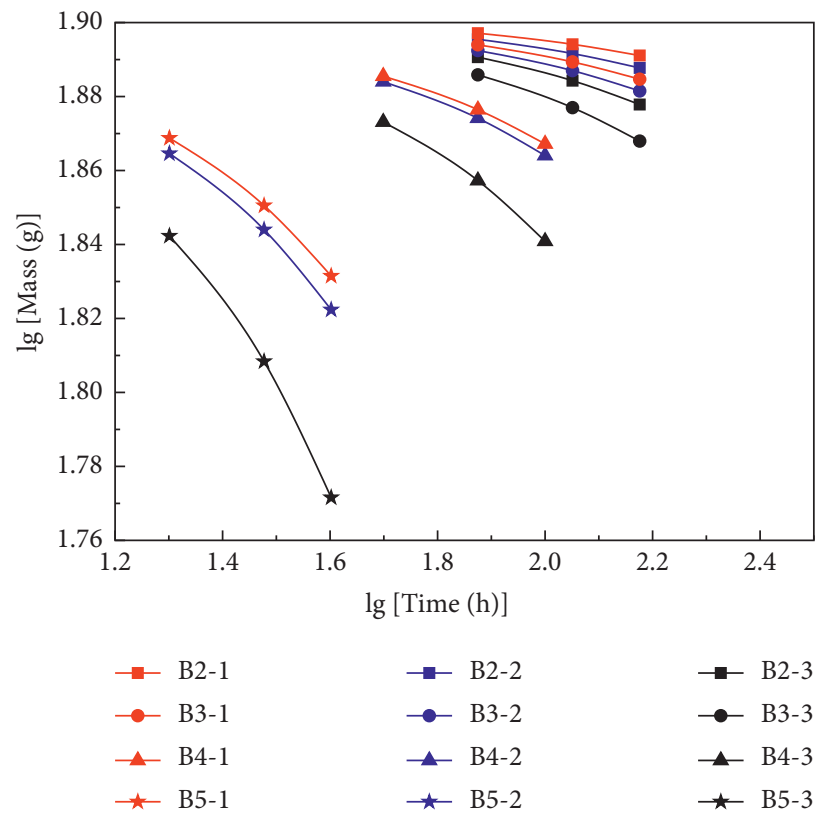

FIgURE 7: Time-residual mass curve of specimens.

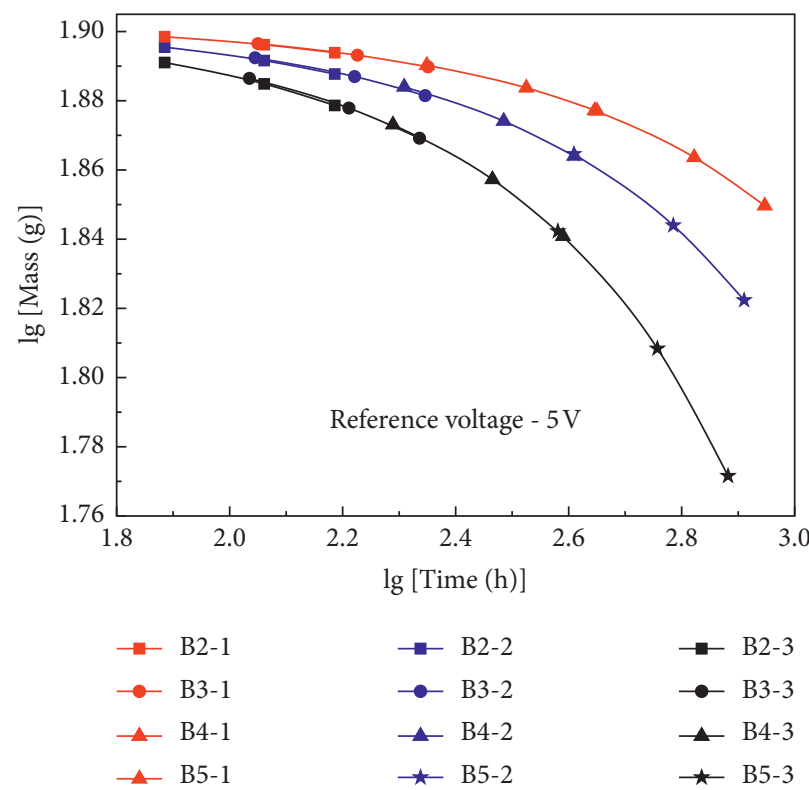

FIgURE 8: Time-residual mass curve of specimens shifted with respect to the reference curve for the applied voltage of $5 \mathrm{~V}$.

from the original $79.47 \mathrm{~g}$ reduces to $59.10 \mathrm{~g}$ after $1028.25 \mathrm{~h}$ $(\log T=3.0121)$. Compared with the $40 \mathrm{~h}$ of the ACT under $35 \mathrm{~V}$ and $5 \%$ chloride content, the accelerated factor $\alpha_{1}$ is 25.71 in this case.

Therefore, the time scale of different chloride concentrations and different voltages of the ACT was achieved and expressed as the ratio of the time corresponding to the component loss of the same degree caused by the ACT and the natural exposure environment. Moreover, the accelerated factor under more conditions can be predicted by the exponential curve relationship of time and mass loss. The corresponding accelerated factors of each condition are shown in Table 5.

As can be seen from Table 5, the accelerated factor increases with the increase of applied voltages and chloride concentrations, and the accelerating effect of applied voltages increases in the low-chloride environment, which is better than that in the high-chloride environment. The accelerated factor is fitted as in equation (13): 


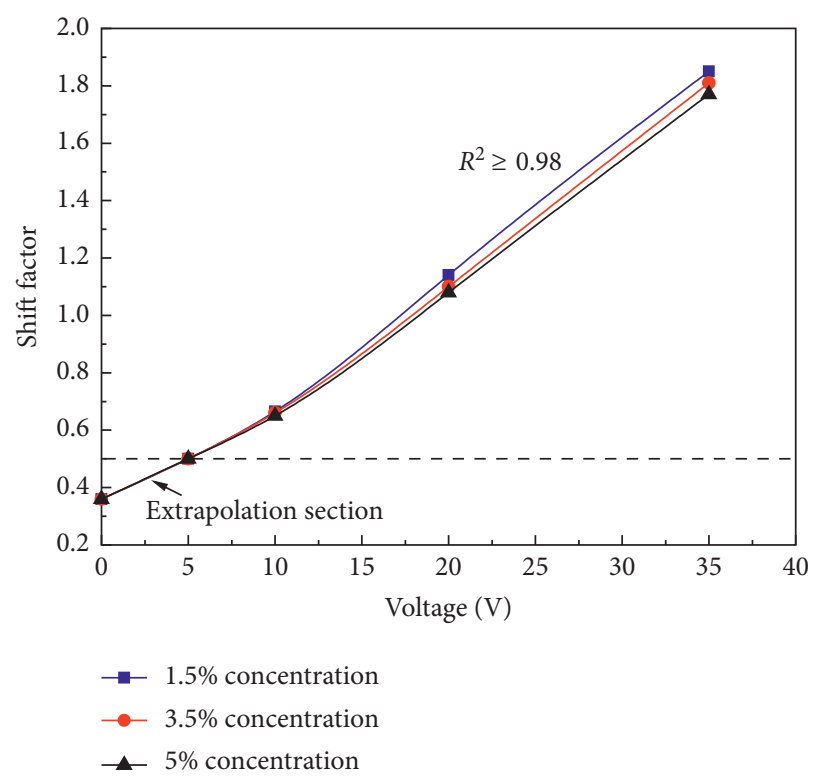

Figure 9: The derivation of the shift factor of $0 \mathrm{~V}$.

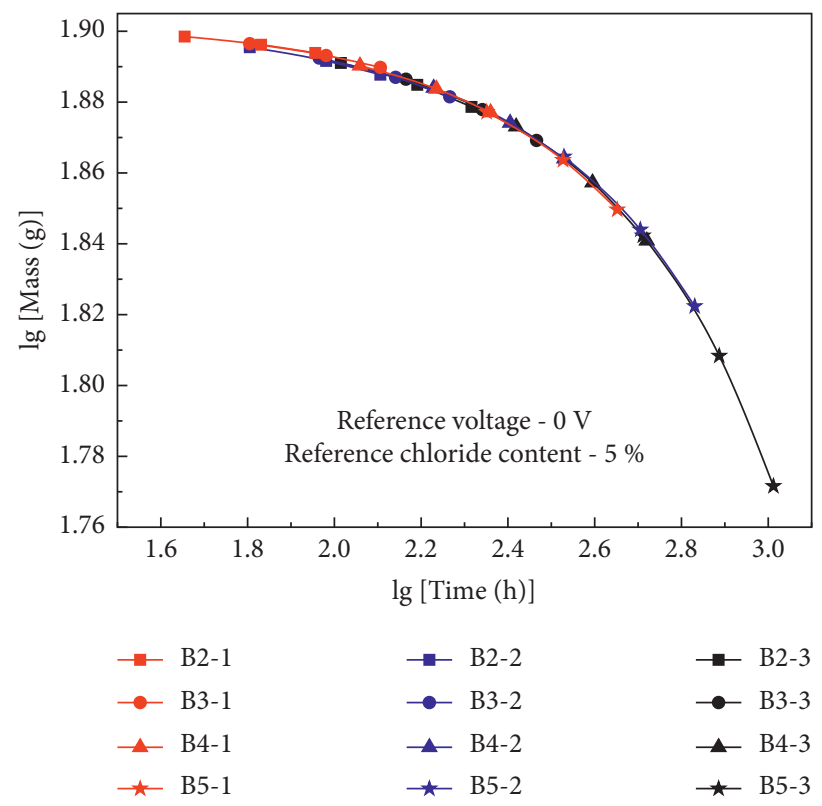

Figure 10: Master curve with 5\% chloride content and $0 \mathrm{~V}$.

$$
\begin{aligned}
\alpha= & 3.084-0.551 v+34.850 c+0.039 v^{2} \\
& -4.035 v c, \quad v>0, c>0
\end{aligned}
$$

where $v$ is the applied voltage and $c$ is the chloride content.

4.3. Prediction Model of Complete Corrosion Process. In summary, the corrosion process consists of corrosion initiation stage and corrosion stage of reinforcement. The corrosion initiation time of steel is related to the shape of the member, the chloride content on the concrete surface, the composition of concrete, and the geographical position of the member. The corrosion time of reinforcement is the product of accelerated factor and time of the ACT. The accelerated factor is determined by applied voltages and chloride concentrations. The key of accelerated corrosion in the first stage is the increase of chloride concentrations. The relationship between the accelerated effect and chloride concentrations is roughly a logarithmic function, but it still needs to be proved by more data points; and for the second stage, the accelerating effect of chloride concentrations is not significant as that of applied voltages. The relevant parameters in equation (15) are given in equations (8)-(11). 
TABLE 5: Accelerated factor.

\begin{tabular}{|c|c|c|}
\hline Chloride concentration (\%) & Voltage (V) & Accelerated factor $(\alpha)$ \\
\hline \multirow{4}{*}{1.5} & 5 & 1.3804 \\
\hline & 10 & 2.0184 \\
\hline & 20 & 6.0256 \\
\hline & 35 & 29.8538 \\
\hline \multirow{4}{*}{3.5} & 5 & 1.3804 \\
\hline & 10 & 1.9953 \\
\hline & 20 & 5.4954 \\
\hline & 35 & 27.4499 \\
\hline \multirow{4}{*}{5.0} & 5 & 1.3804 \\
\hline & 10 & 1.9498 \\
\hline & 20 & 5.2481 \\
\hline & 35 & 25.7040 \\
\hline
\end{tabular}



FIgURE 11: Reinforcement arrangement and size of test pier (Unit: $\mathrm{mm}$ ).

$$
\begin{aligned}
& T=T_{\text {corr }}+\alpha t_{2}, \\
& T=k \cdot \frac{d_{c}^{2}}{4 D}\left[\operatorname{erf}^{-1}\left(1-\frac{C_{c r}}{C_{0}}\right)\right]^{-2}+\left(3.084-0.551 v+34.850 c+0.039 v^{2}-4.035 v c\right) t_{2},
\end{aligned}
$$

Taking the bridge pier in Chaoshan Ring Road as an example [23], the ACT and quasi-static test were carried out on the reduced specimen. The longitudinal nonuniform corrosion in the plastic hinge area highly affects the seismic performance of the structure. Accelerated corrosion was applied to the plastic hinge area of the pier specimens
(Figure 11). The cover depth and diameter of steel bar are consistent with the previous part. Specific parameters of specimens are shown in Table 6; and an uncorroded pier was set as the control group.

The pier specimen D1-1 was tested by the intended sequence, accelerated with small current of 2 days and then 
TABLE 6: Specimen parameters and test matrix.

\begin{tabular}{lcccccccc}
\hline Specimen & Diameter (m) & Reinforcement ratio (\%) & Concrete & Steel & Reduced scale & $\begin{array}{c}\text { Axial } \\
\text { compression ratio }\end{array}$ & Test duration \\
\hline D1-1 & 0.24 & 1.50 & C40 & HRB400 & $1: 6.25$ & 0.057 & $\begin{array}{c}\text { 2d (potentiostatic) + 40d } \\
\text { (galvanostatic) }\end{array}$ \\
D1-2 & 0.24 & 1.50 & C40 & HRB400 & $1: 6.25$ & 0.057 & - \\
\hline
\end{tabular}

TABLE 7: Related parameters of prediction model.

\begin{tabular}{lccccc}
\hline $\begin{array}{l}\text { Coefficient } \\
k)\end{array}$ & $\begin{array}{c}\text { Cover depth }\left(d_{c}\right) \\
(\mathrm{mm})\end{array}$ & $\begin{array}{c}\text { Chloride concentration on the } \\
\text { concrete surface }\left(C_{0}\right)\end{array}$ & $\begin{array}{c}\text { Critical } \\
\text { concentration } ;\left(C_{\mathrm{cr}}\right)\end{array}$ & $\begin{array}{c}\text { Chloride diffusion } \\
\text { coefficient }(D)\end{array}$ & \begin{tabular}{c} 
Accelerated factor $(\alpha)$ \\
\hline 0.972
\end{tabular} \\
20 & $2.95 \mathrm{~kg} / \mathrm{m}^{3}$ & $0.9 \mathrm{~kg} / \mathrm{m}^{3}$ & $21.3 \mathrm{~mm}^{2} / \mathrm{a}$ & 27.85 \\
\hline
\end{tabular}

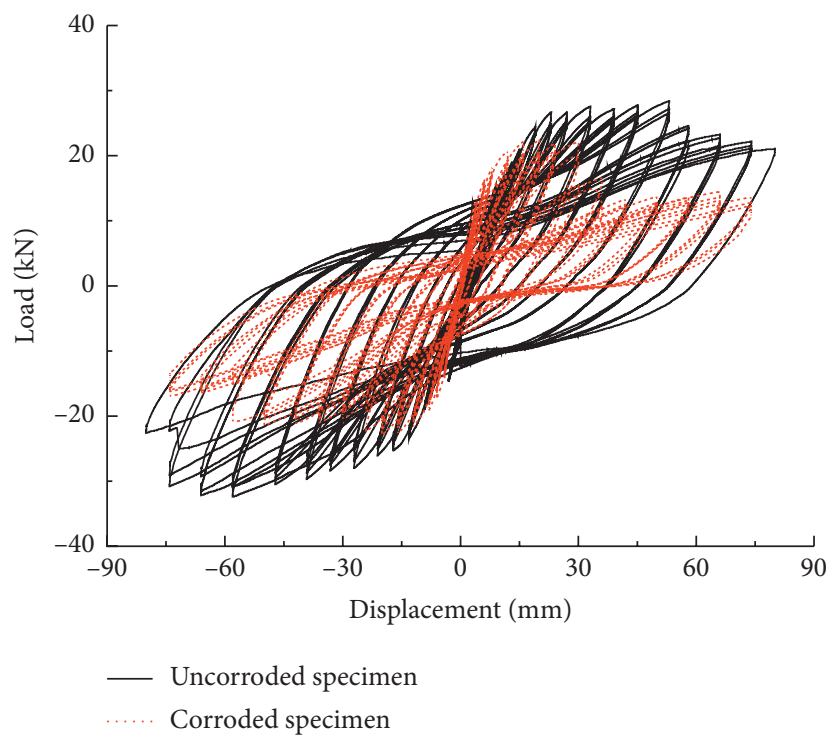

Figure 12: Comparison of hysteresis characteristics between the corroded specimen and uncorroded specimen.

by the potentiostatic method of $35 \mathrm{~V}$ for 40 days $(5 \%$ chloride concentration). The corresponding time-related parameters of natural corrosion can be obtained using equations (8)-(13), as shown in Table 7. Furthermore, the corrosion initiation time of steel in the natural environment was $8.68 \mathrm{a}$, and the natural corrosion time corresponding to the $40 \mathrm{~d}$ of the ACT was $3.05 \mathrm{a}$ The total erosion duration was 11.73a (equations (14) and (15)).

Quasi-static tests were carried out on the corroded and uncorroded specimens, respectively, and the hysteresis curves were obtained as shown in Figure 12.

It can be seen from Figure 12 that the corroded specimen entered into the yield stage prematurely under the pseudostatic test of low cyclic loads compared with the uncorroded specimen [27]. The concrete cover at the bottom of the pier was broken in the early stage, and reinforcement has the shrinkage effect due to the chloride-induced corrosion. The limit displacement of the corroded specimen decreased by $59.9 \%$ compared with that of the uncorroded specimen. Therefore, the seismic performance of the bridge pier will suffer about a loss of $59.9 \%$ after erosion in the natural environment for 9.05a. The prediction model of the complete corrosion process proposed in this paper can be used to accurately calibrate the corresponding natural corrosion time of the specimens after the ACT.

\section{Conclusions}

Time scale of chloride-induced corrosion on circular section RC linked accelerated test to natural corrosion was studied with different chloride concentrations and different applied voltages. Current variation, damage degree, and mass loss are analyzed, and the following main findings can be drawn.

(1) A low-current accelerated test before the potentiostatic test is carried out to avoid the effect of anode competition reactions on the efficiency of applied electric energy. The mass loss in the corrosion initiation stage has a logarithmic relation with the chloride. Furthermore, considering the boundary effect, the coefficient of chloride diffusion model for the circular section member is proposed. 
(2) The time-mass curve of the corrosion stage of reinforcement under a natural exposed environment is deduced by the assumption of Arrhenius time equivalence and Faraday's law; and the accelerating effect of applied voltages increases in the low-chloride environment, which is better than that in the high-chloride environment.

(3) A novel prediction model of the complete corrosion process comprising corrosion initiation stage and corrosion stage of reinforcement is presented to calibrate the natural exposure time corresponding to the time of ACT.

\section{Data Availability}

The data used to support the findings of this study are included within the article.

\section{Conflicts of Interest}

The authors declare that they have no conflicts of interest.

\section{Acknowledgments}

This work was supported by the National Natural Science Foundation of China (5197081959), Key R\&D Project of Shaanxi Province (2019KW-051), Shaanxi Innovative Talents Promotion Plan-Science and Technology Innovation Team Fund (2018TD-040), and the Fundamental Research Funds for the Central Universities, CHD (300102210513).

\section{References}

[1] Z. P. Bazant, "Physical model for steel corrosion in sea structures-applications," Journal of the Structural Division, vol. 105, pp. 1137-1153, 1979.

[2] S. Guzmán, J. C. Gálvez, and J. M. Sancho, "Modelling of corrosion-induced cover cracking in reinforced concrete by an embedded cohesive crack finite element," Engineering Fracture Mechanics, vol. 93, pp. 92-107, 2012.

[3] H. Yalciner, O. Eren, and S. Sensoy, "An experimental study on the bond strength between reinforcement bars and concrete as a function of concrete cover, strength and corrosion level," Cement and Concrete Research, vol. 42, no. 5, pp. 643-655, 2012.

[4] Y. Kang, G. Li, and Z. Q. Jin, "Corrosion behavior of reinforced bar in concrete in marine environment," Tunnel Construction, vol. 38, no. 12, pp. 1966-1974, 2018.

[5] W. Yuan, A. Guo, W. Yuan, and H. Li, "Experimental investigation on cyclic behavior of coastal bridge piers with nonuniform corrosion under biaxial quasi-static loads," Construction and Building Materials, vol. 190, no. 30, pp. 222-234, 2018.

[6] A. Guo, W. Yuan, H. Li, and H. Li, "Structural strength deterioration of coastal bridge piers considering non-uniform corrosion in marine environments," Earthquake Engineering and Engineering Vibration, vol. 17, no. 2, pp. 429-444, 2018.

[7] Z. Jin, X. Zhao, T. Zhao, and L. Yang, "Interaction between compressive load and corrosive-ion attack on reinforced concrete with accelerated potentiostatic corrosion," Construction and Building Materials, vol. 113, no. 15, pp. 805-814, 2016.
[8] S. Imperatore, Z. Rinaldi, and C. Drago, "Degradation relationships for the mechanical properties of corroded steel rebars," Construction and Building Materials, vol. 148, pp. 219-230, 2017.

[9] G. Nossoni and R. Harichandran, "Current efficiency in accelerated corrosion testing of concrete," Corrosion, vol. 68, no. 9, pp. 801-809, 2012.

[10] J. T. Butke, An Evaluation of a Point Snow Model and a Mesoacale Model for Regional Climate Simulations, Newwark, University of Delaware, Newwark, DE, USA, 1996.

[11] A. Bossio, G. P. Lignola, F. Fabbrocino et al., "Nondestructive assessment of corrosion of reinforcing bars through surface concrete cracks," Structural Concrete, vol. 18, no. 1, pp. 104-117, 2017.

[12] F. Chen, H. Baji, and C.-Q. Li, "A comparative study on factors affecting time to cover cracking as a service life indicator," Construction and Building Materials, vol. 163, no. 2, pp. 681-694, 2018.

[13] A. Dehaoux, F. Bouchelaghem, and Y. Berthaud, "Micromechanical and microstructural investigation of steel corrosion layers of variable age developed under impressed current method, atmospheric or saline conditions," Corrosion Science, vol. 97, pp. 49-61, 2015.

[14] B. Dong, G. Fang, Y. Liu et al., "Monitoring reinforcement corrosion and corrosion-induced cracking by X-ray microcomputed tomography method," Cement and Concrete Research, vol. 100, pp. 311-321, 2017.

[15] S.-M. Chen, B. Cao, Y.-S. Wu, and K. Ma, "Effect of temperature on the passivation behavior of steel rebar," International Journal of Minerals, Metallurgy, and Materials, vol. 21, no. 5, pp. 455-461, 2014.

[16] S. C. Paul and G. P. A. G. van Zijl, "Crack formation and chloride induced corrosion in reinforced strain hardening cement-based composite (R/SHCC)," Journal of Advanced Concrete Technology, vol. 12, pp. 340-351, 2014.

[17] P. Quandalle, P. Chastanet, and A. G. Prevost, "Modelling chloride penetration in concrete using electrical voltage and current approaches," Materials Research, vol. 14, pp. 31-38, 2011.

[18] Z. P. Bazant, "Theory and creep and shrinkage in concrete structures: a precis of recent developments," in Mechanics Today, S. Nemet-Nasser, Ed., Pergamon Press, Oxford, UK, 1975.

[19] B. H. Oh and S. W. Cha, Realistic Models for Degree of Hydration and Moisture Distribution in Concrete at Early Age, Swets \& Zeitlinger, Lisse, The Netherlands, 2001.

[20] A. Caceres, R. M. Jamond, and T. A. Hoffard, Accelerated Testing of Fiber Reinforced Polymer Matrix Composite, p. 11, Naval Facilities Engineering Service Center, Port Hueneme, CA, USA, 2000.

[21] G. P. A. G. Van Zijl and S. C. Paul, "A novel link of the time scale in accelerated chloride-induced corrosion test in reinforced SHCC," Construction and Building Materials, vol. 167, pp. 15-19, 2018.

[22] S. C. Paul, A. J. Babafemi, and K. Conradie, "Applied voltage on corrosion mass loss and cracking behaviour of steel reinforced SHCC and mortar specimens," Journal of Materials in Civil Engineering, vol. 27, pp. 1-9, 2017.

[23] F. Y. Lan, Study on Seismic Performance of Reinforced Concrete Cylindrical Pier Exposed to Chloride Ion, Xi'an University of Science and Technology, Xi'an, China, 2020.

[24] D. F. Wang, Calculation Method of Initial Corrosion Time of Reinforced Concrete Members under Chloride Ion Erosion, Beijing University of Technology, Beijing, China, 2003. 
[25] K. A. T. Vu and M. G. Stewart, "Structural reliability of concrete bridges including improved chloride-induced corrosion models," Structural Safety, vol. 22, no. 4, pp. 313-333, 2000.

[26] N. P. De Alcantara and F. M. Da Silva, "Corrosion assessment of steel bars used in reinforced concrete structures by means of eddy current testing," Sensors, vol. 16, p. 15, 2016.

[27] A. Bossio, F. Fabbrocino, T. Monetta et al., "Corrosion effects on seismic capacity of reinforced concrete structures," Corrosion Reviews, vol. 37, no. 1, pp. 45-56, 2019. 